\title{
Mitigation of the Factors Affecting the Autogenous Shrinkage of Ultra- High Performance Concrete
}

\author{
Adil M. Jabbar*, Mohammed J. Hamood, Dhiyaa H. Mohammed \\ Civil Engineering Dept., University of Technology-Iraq, Alsina'a street, 10066 Baghdad, Iraq. \\ *Corresponding author Email: 42394@student.uotechnology.edu.iq
}

\section{H I G H L I G H T S}

- In UHPC, autogenous shrinkage dominates over the drying shrinkage.

- High pouring temperature and coarse sand increase the number and size of pores.

- Increasing silica fume over $25 \%$ of cement content reduces compressive strength.

- Adding steel or basalt fibers minimize the inverse effect of autogenous shrinkage.

\section{A R T I C L E I N F O}

Handling editor: Wasan I. Khalil

\section{Keywords:}

Autogenously shrinkage

Cement

Fly ash

HRWRA

Silica fume

UHPC

\section{A B S T R A C T}

Ultra-High Performance Concrete (UHPC) is a new generation of concrete characterized by its high strength, high durability, and high stiffness. Autogenously shrinkage represents one of the issues of UHPC that occurred at early ages. It occurs particularly during the first 48 hours after casting. This paper focuses on the ways that can be depended on to mitigate the autogenously shrinkage and obtain the outstanding mechanical properties of UHPC. The results showed that the use of coarse sand and high dose of high range water reduced the admixture above $5 \%$ of cementations of materials weight, and high ambient temperature at the time of mixing and casting led to increasing the autogenously shrinkage. While using fine sand, silica fume at $25 \%$ of cement weight, and crushed ice at $50 \%$ of mixing water to control the mixing temperature can reduce autogenously shrinkage significantly.

\section{Introduction}

The modern generation of concrete called ultra-high-performance concrete (UHPC) depends primarily on optimizing the packing density [1]. Packing density refers to the mixing design method. For the substance that consists of many components like concrete, the particles of the components should be carefully selected to fill up the voids among other particles by using smaller ones per each size $[2,3,4]$. This should be done to reach a dense and sound particle structure. The coarse aggregate is omitted in UHPC to attain the best packing density $[3,5]$. Therefore, UHPC consists of a large quantity of cement to compensate for the absence of coarse aggregate, perfect percentages of other cementations materials, such as silica fume and fly ash, low water to cementations materials $(\mathrm{w} / \mathrm{cm})$ ratio at a range of 0.2 or less, high dose of high range water reducing admixture (HRWRA), fine sand as well as fibers [1, 6, 7]. Each component has a specific role and a general one that participates with the other constituents to develop the properties of the resulting compound [1, 2]. Hisham and Oday [8] stated that using silica fume at $10 \%$ to partially replace the cement content can improve the mechanical properties of high strength concrete. Ahmad et al. [9] showed that adding fibers to the concrete can improve the tensile strength more than compressive one. Ahmed et al. [10] showed that the use of fibers increased the toughness of cement. The function and significance of each component are shown in Figure 1 [2, 3, and 5].The low w/cm ratio, high cement content, and using fine cementations materials result in self-desiccation inside the microstructure, which may cause micro-cracking in the hardened concrete [11,12]. Autogenously shrinkage is considered as an associated issue with high strength materials, especially at early ages [11]. The concrete shrinkage usually occurs due to water loss by evaporation and chemical reactions resulting from cement hydration. In conventional concrete having a high $\mathrm{w} / \mathrm{c}$ ratio, the drying shrinkage dominates over autogenously shrinkage. While in UHPC with a lower w/cm ratio, the autogenously shrinkage dominates [12, 13]. Autogenously shrinkage can be defined as macro 
volume changes occurred due to low water content which induces a capillary pressure and leads to forming glimmer voids. It results from self-desiccation and reactions of cementations materials hydration [14].

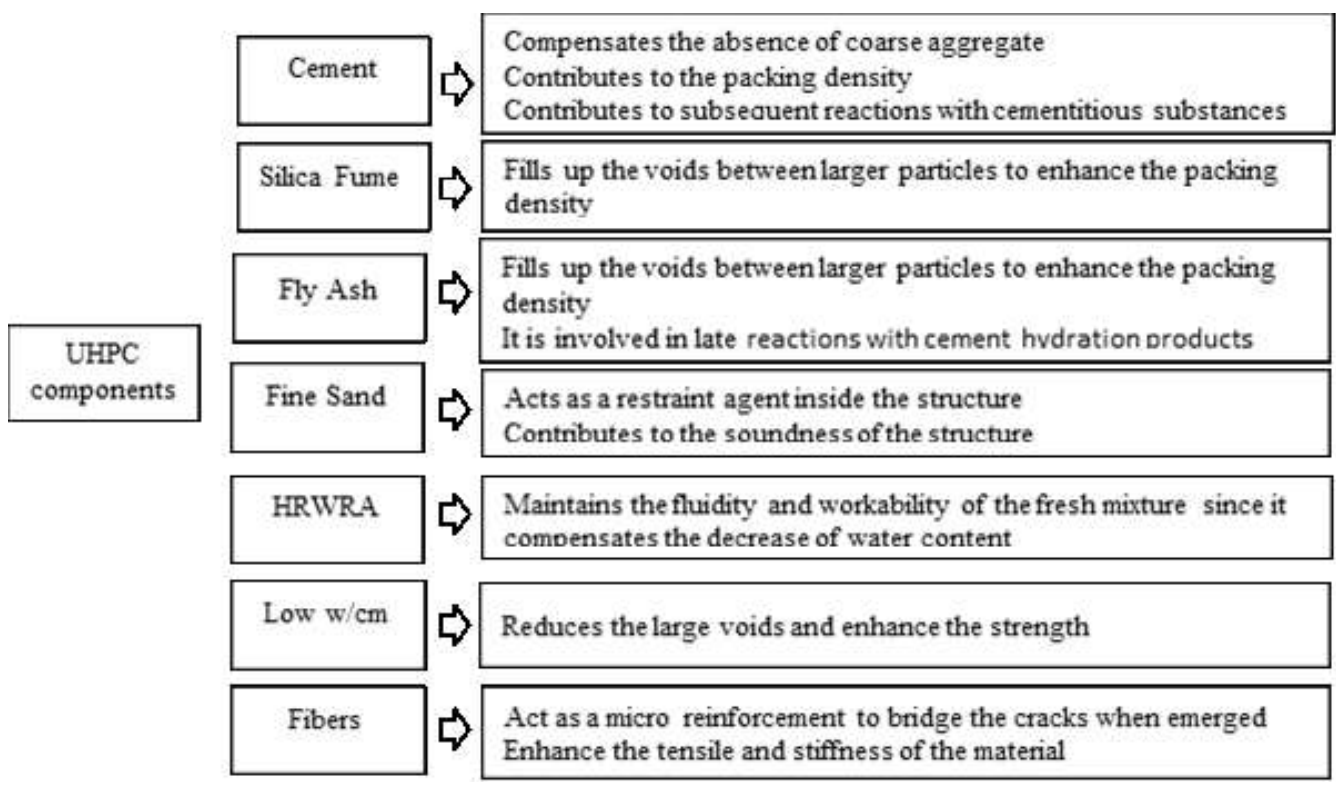

Figure 1: The main components of UHPC and their significance $[2,3,5]$

Despite the outstanding properties that UHPC possesses, high autogenously shrinkage might occur during the first 48 hours after casting. This shrinkage occurs because of the initial hydration that may cause hairline cracks at early ages [11]. Many factors influence the autogenously shrinkage such as; the size of fine aggregate used, the dose of high range water reducing admixture, the ambient temperature, the percent of cementations materials used, and the use of fibers as a micro reinforcement inside the matrix. Despite the efforts carried out by many researchers to reduce the inverse effects of autogenously shrinkage, there is still a need for more research because most of these research works relied on the incorporation of supplementary materials to mitigate the shrinkage. This research focuses on studying the factors that affect the presence of autogenously shrinkage in UHPC and the possible ways to minimize its inverse effects on the mechanical properties by adjusting the mix proportions and without other additives.

\section{The possible ways to reduce the impact of autogenously shrinkage}

It is memorable that there are several techniques used by several researchers to reduce the impact of autogenously shrinkage. Xie et al. [15] studied the efficiency of three different ways to reduce the effect of shrinkage. These techniques were:

1) Decreasing the content of the cementations materials.

2) Using a high percentage of shrinkage reducing admixtures (SRA).

3) Using crushed ice to replace a part of mixing water.

The results of Xie et al. [15] indicated that increasing the cementations materials-to-sand (cm/s) ratio decreased the autogenously shrinkage. This decrease was due to the restraint provided by the non-reactive cementations materials in the composition of UHPC. The researchers suggested that the optimum $(\mathrm{cm} / \mathrm{s})$ ratio was $(1.0-1.1)$, which causes reducing the shrinkage effect. Moreover, Xie et al. [15] indicated that using crushed ice at 50\% of mixing water can minimize the autogenously shrinkage up to $22 \%$. Liu et al. [11] discussed the chemical and physical causes of autogenously shrinkage. The authors explained that the water content in the matrix gradually decreased with time due to the hydration of cement and other cementations materials leading to chemical shrinkage. Volume changes occur in the microstructure due to the shrinkage, which leads to creating voids inside the structure of UHPC. This phenomenon continues with the progressing of hydration to result in the formation of a large number of voids in the hardened UHPC. Liu et al. [11] suggested some methods to reduce the autogenously shrinkage. These methods considered the addition of other cementations materials to hinder the early hydration and reduce the associated heat like fly ash and met kaolin, using crushed ice and lightweight aggregate for the purpose of internal curing, and increasing tensile strength by steel fibers. Kamen [13] and Hanet et al. [16] stated that the high initial curing temperature raised the rate of autogenously shrinkage. Yang et al. [14] showed the approaches that can be followed to mitigate the autogenously shrinkage depending on restraining agents inside the structure of UHPC. These approaches included the addition of other materials such as supplementary cementations materials to replace part of cement, shrinkage reducing agent, expansive agent, and superabsorbent polymer to replace the aggregate. 


\section{Experimental investigation}

The experiments consist of using variable proportions of ingredients. The raw materials used in this work included; ordinary Portland cement, condensed silica fume, fly ash, rounded quartz sand with a compact density of $2650 \mathrm{~kg} / \mathrm{m}^{3}$, HRWRA of carboxylate ether polymer base with a specific gravity of 1.123 , round-straight steel fibers of $12 \mathrm{~mm}$ length and $0.2 \mathrm{~mm}$ diameter with $2800 \mathrm{MPa}$ tensile strength, and chopped basalt fibers of 0.16-0.18 mm diameter and $12 \mathrm{~mm}$ length. Figure 2 shows the materials used in the experiments. The properties of cement, silica fume, and fly ash are presented in Table 1.The mitigation of passive effects of autogenously shrinkage on UHPC has been studied by adopting the modifications in the types of the materials, their proportions, and controlling the placing and initial curing temperatures. Despite using an appropriate proportion of raw materials, an autogenously shrinkage issue occurred in UHPC. Therefore, many factors that influence the autogenously shrinkage of UHPC are considered in this study. These factors are as follows:

a) The size of sand particles: At the beginning, two gradations of quartz sand were considered $(0.08-0.2) \mathrm{mm}$ and $(0.3-0.7) \mathrm{mm}$ at percentages of fine to coarse sand as 1:1, 1:1.2, 1:0.85, and 1:0.67. Then, just fine sand of (0.08-0.2) mm was used.

b) The ambient temperature: The surrounding ambient temperature was at a range between $(36-44){ }^{\circ} \mathrm{C}$. Thereafter, it was reduced to $(22-28)^{\circ} \mathrm{C}$ by cooling the room.

c) The percentage of silica fume: Five percentages of SF were tried $(0.428,0.40,0.30,0.25$, and 0.20$)$.

d) The cement content: 770 and $1000 \mathrm{~kg} / \mathrm{m}^{3}$ cement content was used throughout the mixtures of experiments. Thereafter, it was decided to use $1000 \mathrm{~kg} / \mathrm{m}^{3}$ cement content.

e) The use of fly ash to improve workability. Then it was disregarded.

f) The percentage of HRWRA: Five percentages; $8 \%, 6 \%, 5 \%, 4 \%$, and $2 \%$ of cementations materials contents were tried to reach the optimum dosage.

g) Incorporating steel or basalt fibers to increase the tensile strength.

Table 1: Chemical analysis and physical properties of cement, silica fume and fly ash

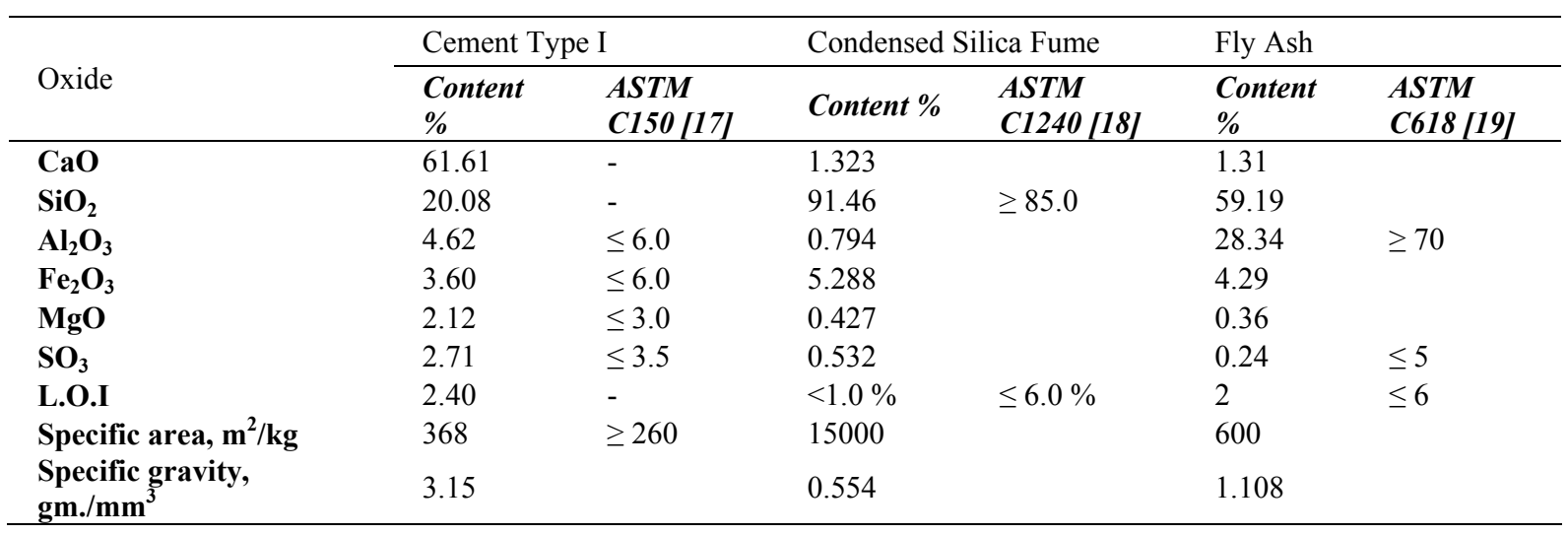

A rotary pan mixer of $0.12 \mathrm{~m} 3$ capacity that has variable speed was used in the preparation of the UHPC mixtures as shown in Figure 3. The mixing procedure of steel fibrous UHPC differs from that of basalt fibrous. For steel fibrous UHPC, the dry constituents of cement, SF, and fly ash were mixed firstly, followed by adding the sand, then half mixing water was added with continuous mixing. The other half mixing water was blended with HRWRA and divided into four quarters, three quarters were added sequentially until reaching homogenous slurry. Finally, the steel fibers were added followed by adding the fourth quarter of blended water and HRWRA with continuous mixing. The period of mixing extended to about (34-40) minutes for each batch. In the case of using basalt fibers, the dry sand was blended with basalt fibers at the first step of the mixing process. Then, premixed cement, SF, and FA were added followed by adding half mixing water. The other steps were similar to the previous method of mixing steel fibrous UHPC. The mixing period in the case of using basalt fibers extended more than that of steel fibers. The total time was about (40-50) minutes per basalt fibrous UHPC batch. The mixing period depended on the quantity of ingredients and the quality of mixer. It was divided into stages according to the addition of ingredients. Onset de-agglomerate the condensed silica, then to ensure adequate time for fluidity, and laterally the slowly addition of the fibers was done. ACI 239R [3] stated that the time required for mixing UHPC is more than 20 minutes or until distributing the constituents and producing a fluid mixture. Arora et al. [20] reached 28 minutes to produce a small size mixture of UHPC. Standard cylinders of $(100 \times 200) \mathrm{mm}$, cubes $(100 \times 100 \times 100) \mathrm{mm}$, prisms $(70 \times 70 \times 260) \mathrm{mm}$ were used for testing the UHPC specimens as indicated in Figure 4. Before casting the UHPC, all molds were cleaned, slightly oiled, and then wiped with a rag to remove extra oil. The prepared mixture was cast in the molds in two layers. Each layer was vibrated for (20-30) seconds by an electrical vibrating table. The top surface of the specimens was well leveled by a steel trowel. Then the specimens were completely covered by double polyethylene sheets to avoid water evaporation. After 24 hours of casting, the hardened specimens were de-molded. Afterward, the samples were put into heat water at $60^{\circ} \mathrm{C}$ temperature for the period of curing. After that, the specimens were taken out of the water and left at room temperature until the testing stage. The tests were for predicting the strength and inspecting the internal structure at the ages indicated in Table 2 . The autogenously shrinkage was 
estimated according to the resulting strength of the tested specimen and examination of the interior entity. It was characterized by many shiny voids that indicate autogenously shrinkage, as shown in Figure 5.
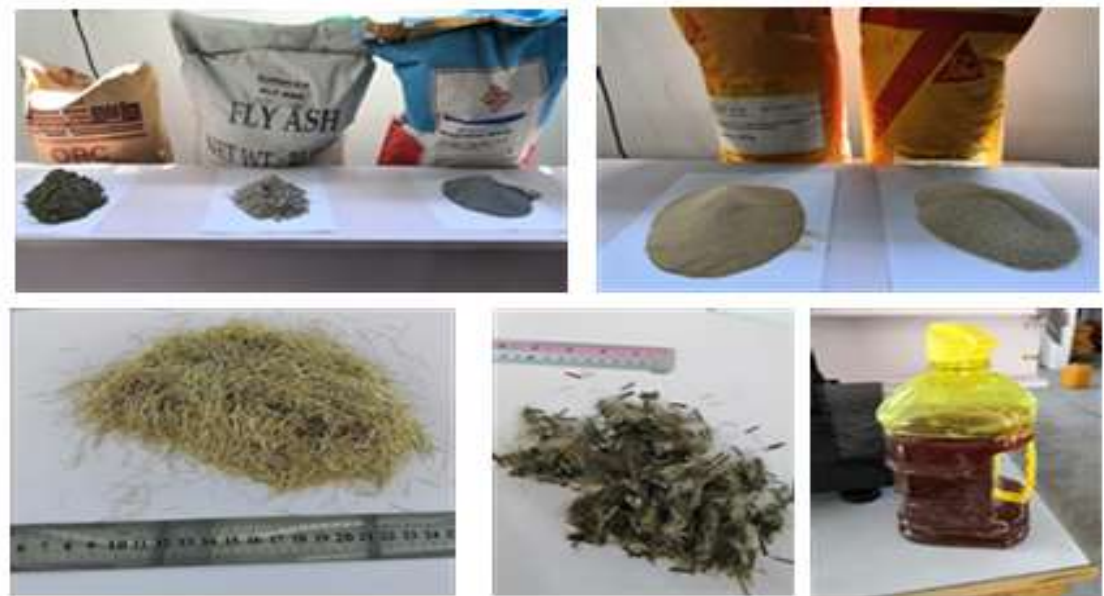

Figure 2: The materials used in experiments; cement, fly ash, silica fume, fine sand, coarse sand, steel fibres, basalt fibres, and HRWRA
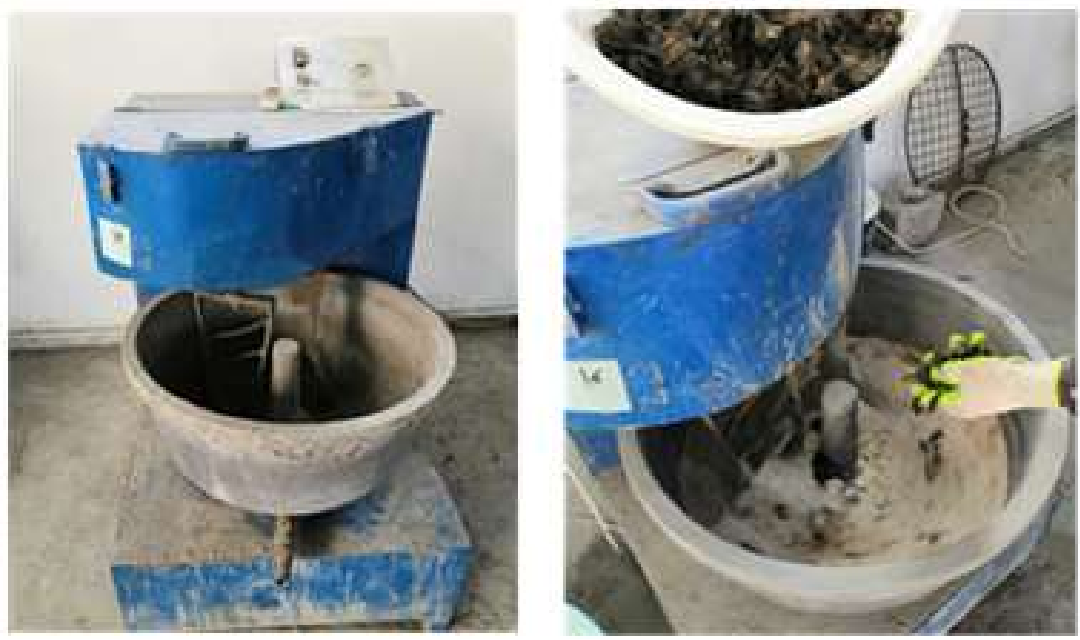

Figure 3: The rotary pan mixer used in experiments
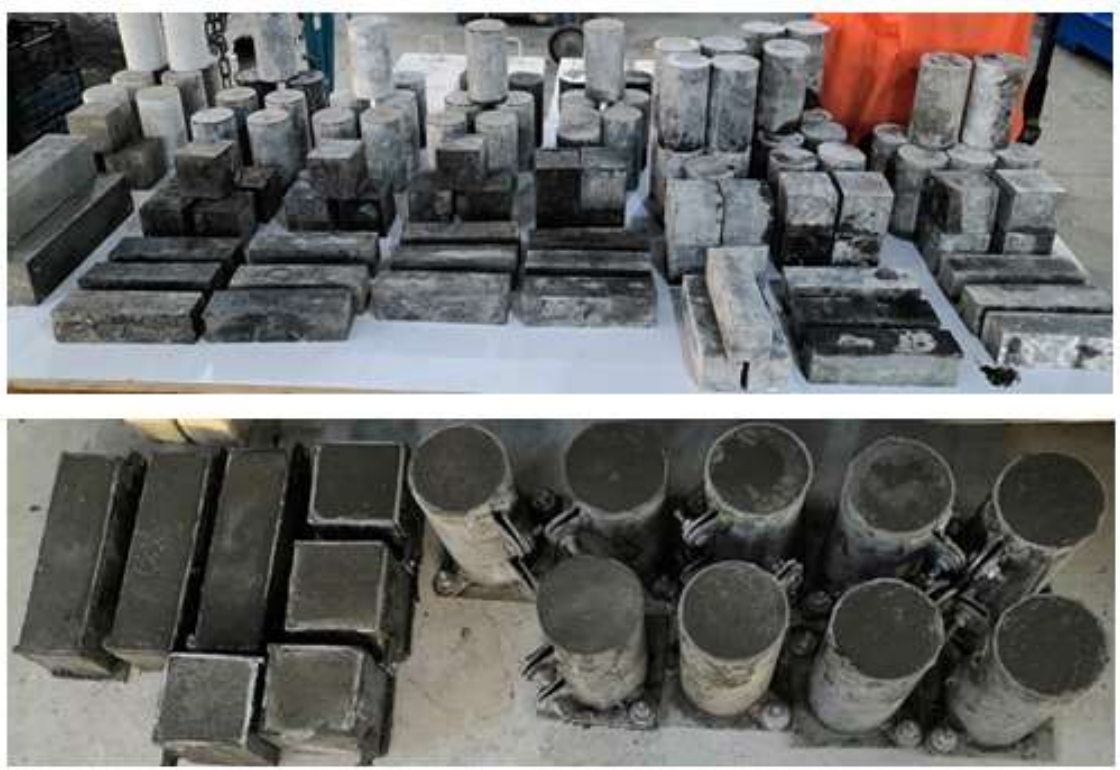

Figure 4: The UHPC specimens that were prepared for testing 


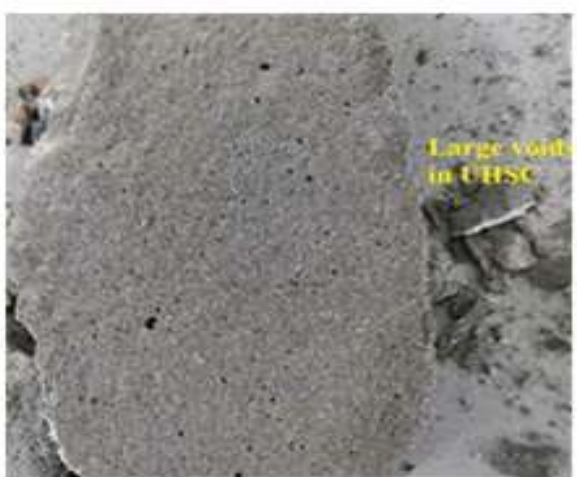

-

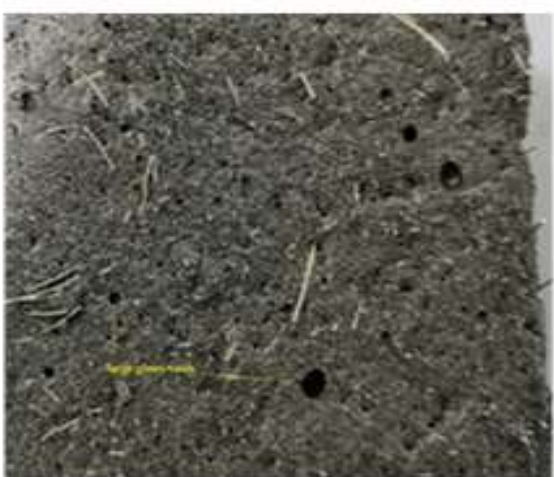

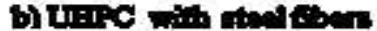

Figure 5: The voids in UHSC and UHPC because of autogenously shrinkage UHSC: Ultrahigh strength concrete

\section{Results and Discussion}

The proportions of materials in the mixtures that were performed are illustrated in Table 2, with the strength of the specimens at the ages indicated. The observations recorded after testing the specimens are shown in Table 3 . In the first group of the mixtures, two gradations of quartz sand were used, (0.08-0.2) $\mathrm{mm}$ as fine sand and (0.3-0.7) $\mathrm{mm}$ as coarse sand. Also, cement (Cem), condensed silica fume (SF), fly ash (FA), high range water reducing admixture (HRWRA) with variable dosages to get the appropriate flow ability, and fibers (steel or basalt) were used. In the second group, coarse sand and fly ash were omitted.

Table 2: Trial mixture proportions and mechanical properties of the specimens

\begin{tabular}{|c|c|c|c|c|c|c|c|c|c|c|c|c|}
\hline $\begin{array}{l}\mathrm{Mi} \\
\mathrm{x} \\
\text { No } \\
.\end{array}$ & $\begin{array}{l}\text { Cem. } \\
\text { Cont. } \\
\mathrm{kg} / \mathrm{m} \\
3\end{array}$ & $\begin{array}{l}\mathrm{SF} / \\
\text { Cem }\end{array}$ & $\begin{array}{l}\text { FA/ } \\
\text { Cem }\end{array}$ & $\begin{array}{l}\text { Fine/ } \\
\text { coarse } \\
\text { sand }\end{array}$ & $\begin{array}{l}\text { Cem/ } \\
\text { sand }\end{array}$ & $\begin{array}{l}\mathrm{w} / \mathrm{c} \\
\mathrm{m}\end{array}$ & $\begin{array}{l}\text { HRWRA } \\
\%\end{array}$ & $\begin{array}{l}\text { Vf } \\
\%\end{array}$ & $\begin{array}{l}\text { Ag } \\
\mathrm{e} \\
\text { day } \\
\mathrm{s}\end{array}$ & $\begin{array}{l}\text { fcf' } \\
\mathrm{MPa}\end{array}$ & $\begin{array}{l}\text { fspf } \\
\mathrm{MPa}\end{array}$ & $\begin{array}{l}\text { frf } \\
\mathrm{MPa}\end{array}$ \\
\hline 1 & 770 & 0.43 & 0.10 & 1.0 & 0.70 & 0.22 & 2 & - & 7 & 37.12 & - & - \\
\hline 2 & 770 & 0.43 & 0.10 & 1.0 & 0.70 & 0.24 & 8 & - & 7 & 57.13 & - & - \\
\hline 3 & 770 & 0.43 & 0.10 & 1.2 & 0.64 & 0.22 & 6 & - & 7 & 60.33 & - & - \\
\hline 4 & 770 & 0.43 & 0.10 & 0.85 & 0.64 & 0.24 & 8 & - & 7 & 54.21 & - & - \\
\hline 5 & 770 & 0.43 & 0.10 & 1.0 & 0.64 & 0.22 & 6 & - & 7 & 66.10 & - & - \\
\hline 6 & 770 & 0.40 & 0.10 & 0.67 & 0.64 & 0.22 & 6 & - & 7 & 63.74 & - & - \\
\hline 7 & 1000 & 0.25 & 0.10 & 1.0 & 1.0 & 0.24 & 8 & 1.0 & 8 & 81.15 & - & 12.3 \\
\hline 8 & 1000 & 0.25 & 0.10 & 1.0 & 1.0 & 0.24 & 8 & - & 8 & 54.00 & - & 9.8 \\
\hline 9 & 1290 & 0.20 & 0.08 & 1.0 & 1.29 & 0.21 & 5 & & 8 & 94.30 & - & - \\
\hline 10 & 1000 & 0.25 & 0.10 & 1.0 & 1.0 & 0.21 & 5 & & 8 & 61.05 & - & - \\
\hline 11 & 1000 & 0.25 & - & 1.0 & 1.0 & 0.21 & 5 & & 8 & 89.40 & - & - \\
\hline 12 & 1000 & 0.25 & - & $-*$ & 1.0 & 0.2 & $4 * *$ & & 9 & 119.46 & - & 13.0 \\
\hline 13 & 1000 & 0.30 & 0.1 & $-*$ & 1.0 & 0.2 & $4 * *$ & & 9 & 105.21 & 12.1 & 13.6 \\
\hline 14 & 1000 & 0.25 & - & $-*$ & 1.0 & 0.2 & $4 * * *$ & & 9 & 137.37 & - & - \\
\hline 15 & 1000 & 0.25 & - & - & 1.0 & 0.2 & 4 & $0.5 \div$ & 75 & 112.53 & 14.7 & 20.0 \\
\hline 16 & 1000 & 0.25 & - & - & 1.0 & 0.2 & 4 & $1.0 \div$ & 75 & 126.89 & 18.1 & 23.6 \\
\hline 17 & 1000 & 0.25 & - & - & 1.0 & 0.2 & 4 & $1.5 \%$ & 75 & 137.18 & 19.8 & 25.0 \\
\hline 18 & 1000 & 0.25 & - & - & 1.0 & 0.2 & 4 & $0.5+t$ & 75 & 148.81 & 12.7 & $\begin{array}{l}17.1 \\
4\end{array}$ \\
\hline 19 & 1000 & 0.25 & - & - & 1.0 & 0.2 & 4 & $1.0+t$ & 75 & 156.42 & 8.5 & $\begin{array}{l}17.7 \\
4\end{array}$ \\
\hline 20 & 1000 & 0.25 & - & - & 1.0 & 0.2 & 4 & $1.5 t t$ & 75 & 145.34 & 8.3 & $\begin{array}{l}17.5 \\
2\end{array}$ \\
\hline \multicolumn{13}{|c|}{$\begin{array}{l}* \text { Only fine sand }(0.08-0.2) \text { was used in the mixture } \\
* * \text { Viscocrete } 5930 \mathrm{~L} \text {, superplasticizer type was used } \\
* * * \text { Hi-tech } 1316 \text {, superplasticizer type was used } \\
+ \text { steel fibers type was used } \\
+t \text { basalt fibers type was used }\end{array}$} \\
\hline
\end{tabular}


Table 3: Observations of the prepared mixtures

\begin{tabular}{|c|c|}
\hline $\begin{array}{l}\text { Mix. } \\
\text { No. }\end{array}$ & Alterations in proportions of mixtures and observations \\
\hline \multirow{2}{*}{1} & A semi-dry mixture in the fresh stage. \\
\hline & High porosity and large pores inside the hardened structure. \\
\hline \multirow{2}{*}{2} & Soft mixture for more than 48 hours due to high dosage of HRWRA \\
\hline & High porosity inside its structure. \\
\hline 3 & $\begin{array}{l}\text { Increasing fine/coarse sand ratio, increasing sand/cement ratio with minimizing HRWRA to } 6 \% \text { reduced } \\
\text { workability. High porosity with large pores. }\end{array}$ \\
\hline 4 & $\begin{array}{l}\text { Increasing coarse sand percentage over fine one with the high dosage of HRWRA ( } 8 \%) \text { led to a slurry } \\
\text { mixture. But, with high porosity and large pores. }\end{array}$ \\
\hline 5 & $\begin{array}{l}\text { Equal contents of fine and coarse sand with the high dosage of HRWRA (6\%) led to a slurry mixture. But, } \\
\text { with high porosity and large pores. }\end{array}$ \\
\hline 6 & Decreasing SF percentage with increasing coarse sand over fine. High porosity. \\
\hline 7 & $\begin{array}{l}\text { Increasing cement content by } 30 \% \text {, decreasing SF/cement with the high dose of HRWRA that minimizes the } \\
\text { porosity. But still, there were large pores despite raising the compressive strength. }\end{array}$ \\
\hline 8 & High porosity with a reduction in the strength. \\
\hline 9 & $\begin{array}{l}\text { Increasing cement content by } 67.5 \% \text {, with decreasing SF/cement that increased compressive strength } \\
\text { significantly. But, it is still less than the desired strength. }\end{array}$ \\
\hline 10 & $\begin{array}{l}\text { Increasing cement content by } 30 \% \text {, decreasing SF/cement ratio to } 25 \% \text {, minimizing the dose of HRWRA to } \\
5 \% \text {, and equality of coarse and fine sand content. High porosity with low compressive strength. }\end{array}$ \\
\hline 11 & $\begin{array}{l}\text { Omission of coarse sand with minimizing the dose of HRWRA to } 5 \% \text { that gave soft mixture for more than } 24 \\
\text { hours but, this procedure decreased porosity and size of pores and enhanced compressive strength. }\end{array}$ \\
\hline 12 & $\begin{array}{l}\text { Omission of coarse sand with minimizing the dose of HRWRA to } 4 \% \text { and using another type of HRWRA } \\
\text { that gave good flow ability, decreased porosity and size of pores, and enhanced compressive strength } \\
\text { significantly. But, till now, fa } \mathrm{c}_{\mathrm{ce}} \text { is less than the desired strength. }\end{array}$ \\
\hline 13 & The addition of fly ash again improved the workability and gave a soft mixture for slightly a long period. \\
\hline 14 & The best proportions of ingredients gave the best results in the fresh and hardened phase. \\
\hline $15-17$ & The used steel fibers enhanced the compressive strength, and reduced the autogenously shrinkage. \\
\hline $18-2$ & $\begin{array}{l}\text { Using basalt fibers enhanced the compressive strength and reduced the autogenously shrinkage significantly } \\
\text { more than that of steel fibers. }\end{array}$ \\
\hline
\end{tabular}

The observations and the results obtained from the mixtures to reduce autogenously shrinkage and produce UHPC with outstanding features and the best mechanical properties can be summarized as follows:

1) Increasing HRWRA dosage up to $8 \%$ resulted in delaying the final setting for more than 48 hours and had an inverse effect on the autogenously shrinkage and strength as indicated schematically in Figure 6.

2) The high pouring temperature caused by ambient and the heat emitted from the cement hydration (with its large quantity) leads to high autogenously shrinkage which was recognized by forming spherical bubbles and meniscus pores inside the formative structure of the hardened UHPC. The compressive strength at 7 days decreased to $41.6 \%$ of the target strength (here target compressive strength $=137.37 \mathrm{MPa}$ ) as indicated schematically in Figure 7.

3) Using fine $(0.08-0.2) \mathrm{mm}$ and coarse $(0.3-0.7) \mathrm{mm}$ sand at percentages of 1.0, 1.2, and 0.67 led to the occurrence of numerous large-size pores, which refer to high autogenously shrinkage. This can be attributed to the gap between $(0.2-0.3) \mathrm{mm}$ of sand particles that might cause a slightly large interfacial transition zone.

4) The combination of high pouring temperature, high dose of HRWRA (6-8) \%, and using coarse sand (0.3$0.7) \mathrm{mm}$ at about $50 \%$ of sand content resulted in the formation of large-size pores inside the hardened structure of UHPC. This can be explained by the emergence of a gap between small and large particles, which increased the area of the interfacial transition zone between cementations paste and coarse sand particles in the microstructure. The dispersion action of HRWRA with its high content led to delaying the hydration process. Moreover, the low water content led to partial hydration of the cementations materials and caused surface tension at the cementations grain surfaces to form spherical or meniscus pores nearby. This represents the autogenously shrinkage as shown in Figure 5.

5) The omission of coarse sand and using fine sand only with decreasing dosage of HRWRA to $5 \%$ led to decreasing porosity and size of pores which in turn enhance the compressive strength.

6) Increasing silica fume content above $25 \%$ of cement content led to a reduction in compressive strength. This can be explained by the increase of the surface area of fine particles which attract water molecules, as the amount of the available water was little, autogenously shrinkage occurred causing relatively high porosity, as shown in Figure 8.

7) Increasing silica fume content up to $30 \%$ of cement content caused reducing compressive strength by about $12.4 \%$. Also, the increase of silica fume content up to (40-42.8) \% of cement content decreased compressive strength by more than $50 \%$. Non-reactive silica fume was also seen to remain in the hardened concrete. 
8) Increasing the cement content above $1000 \mathrm{~kg} / \mathrm{m}^{3}$ and decreasing silica fume content to $20 \%$, led to raising compressive strength slightly. But, anhydrate cement grains remained in the hardened concrete. Therefore, the extra cement was ineffective.

9) The use of coarse sand (0.3-0.7) $\mathrm{mm}$ in the UHPC mixture increased the autogenously shrinkage, which in turn lowered compressive strength. Also, increasing the size of sand in the mixture needs to increase the dosage of HRWRA to attain the desired flow ability of the mixture. This caused delaying the initial setting and increased autogenously shrinkage, which always causes a decrease in the compressive strength.

10) Incorporation of steel fibers or basalt fibers contributes to minimizing the effect of autogenously shrinkage and enhancing the compressive strength as shown in Figures 9 and 10.

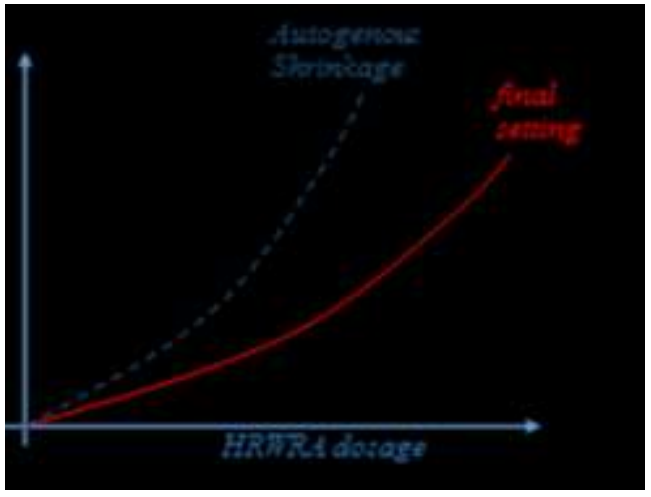

Figure 6: The influence of HRWRA dosage on final setting and on autogenously shrinkage

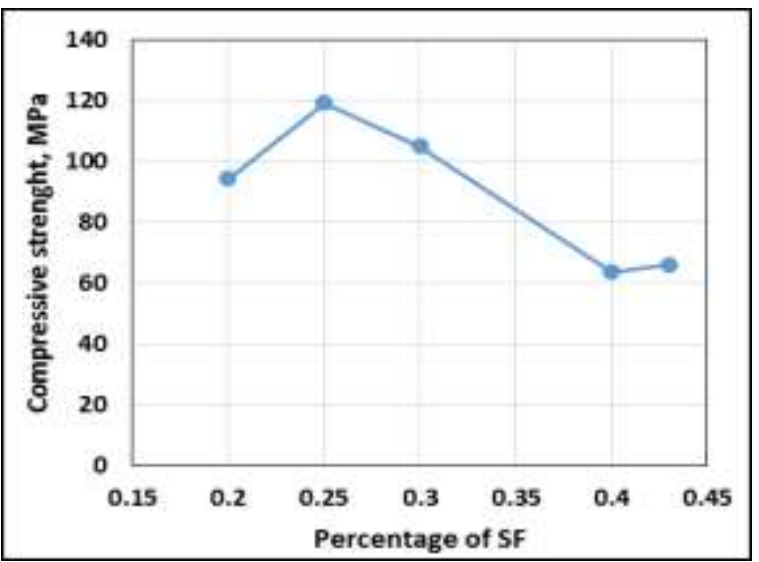

Figure 8: The influence of silica fume content on the compressive strength of UHPC

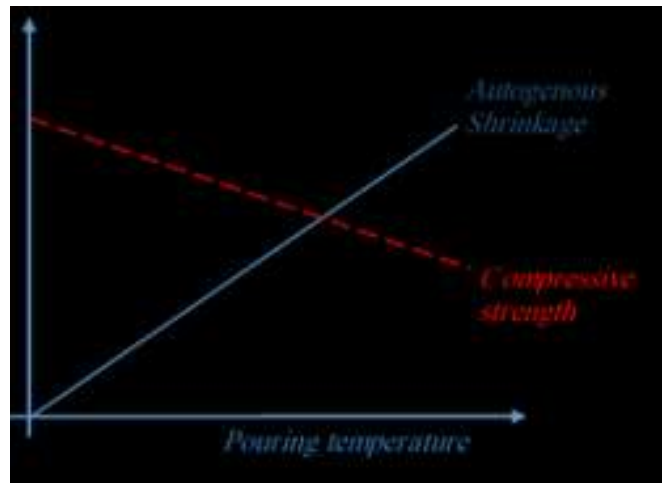

Figure 7: The influence of pouring temperature on autogenously shrinkage and compressive strength

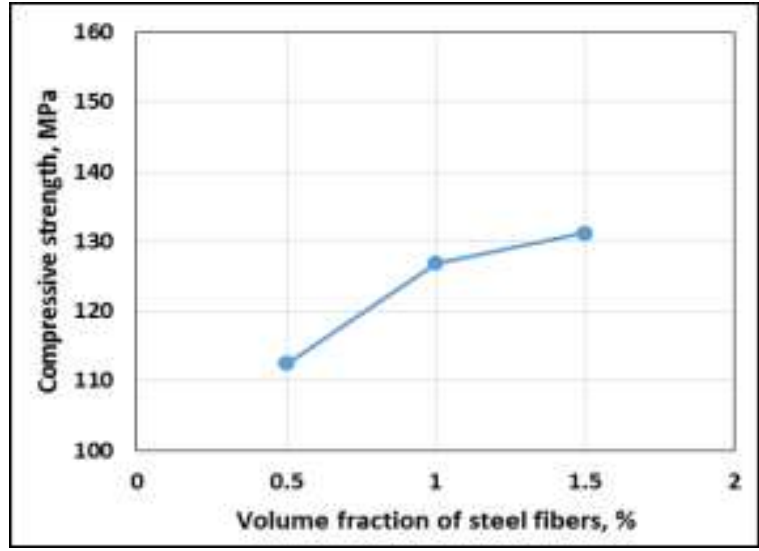

Figure 9: The influence of steel fibres content on the compressive strength of UHPC

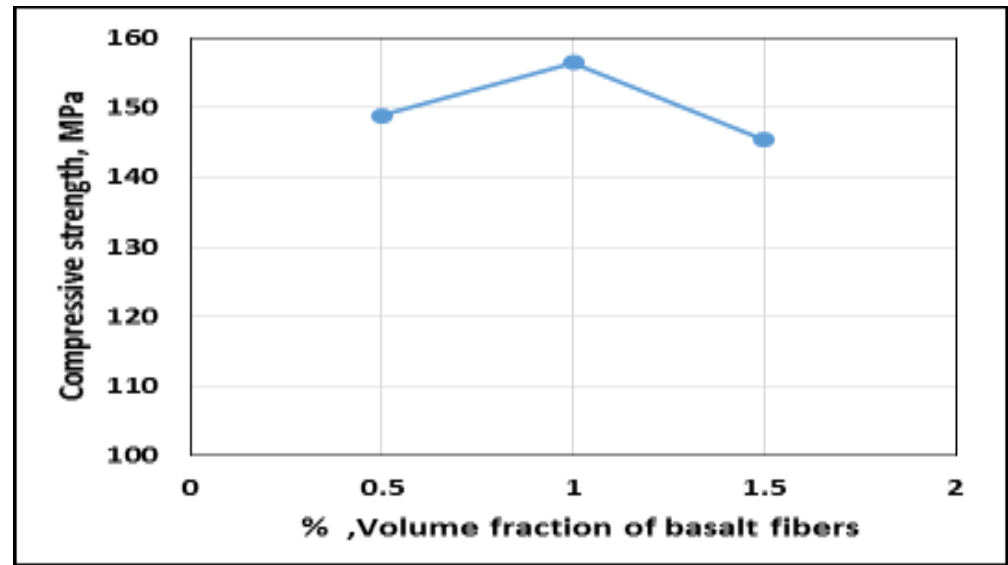

Figure 10: The influence of basalt fibres content on the compressive strength of UHPC 


\section{CONCLUSIONS}

From the results of the mixtures, the following conclusions can be drawn for mitigation of the autogenously shrinkage and production of UHPC:

1) The optimum percentage of cement-to-sand (c/s) was 1.0 .

2) The optimum cement content is $1000 \mathrm{~kg} / \mathrm{m}^{3}$, which could produce the best mechanical properties and reduce autogenously shrinkage significantly.

3) The best HRWRA dosage that gave flow ability of the mixture as a slurry, and reduced autogenously shrinkage, was $4 \%$ of cementations materials content. The above three factors are considered the major factors affecting the reducing of shrinkage.

4) Water-to-cement alone ratio was 0.16 and liquid (water+ HRWRA) to cementations materials (cement + silica fume) ratio was 0.20 . These ratios gave the best mechanical properties in the hardened phase, the best workability, and homogeneity in the fresh phase even when using steel or basalt fibers at a $1.5 \%$ volume fraction.

5) The use of crushed ice at $50 \%$ of water content and keeping the ambient temperature as low as possible for the period from pouring concrete up to about 9 hours after pouring in molds participated significantly to reduce autogenously shrinkage and enhance the mechanical properties.

6) The use of ice as a part of mixing water can equalize or reduce the heat of hydration emitted during the first period after pouring. While decreasing the ambient temperature for 9 hours after casting can restrain the autogenously shrinkage formation.

7) Covering the specimens with two layers of polyethylene caps on all sides helped to keep the water of specimens not evaporating, and keep the temperature as low as possible when they were saved in cooling ambient.

8) The use of fly ash with silica fume in the mixture contributes to improving the flow ability of the mixture. But, inversely affects autogenously shrinkage.

9) This can be attributed to the increase of ultra-fine cementations materials content and their contest to obtain water molecules which may cause an increase in the surface tension on their surface to result in glimmering pores. Therefore, using fly ash in the UHPC mixture can be omitted without inverse effects on the mechanical properties of hardened concrete.

10)Reducing the water content by increasing the dose of HRWRA to keep the same workability, increases autogenously shrinkage rate compared to increasing water content and reducing HRWRA amount for the same total liquid quantity. Therefore, the optimum dose of HRWRA was limited to be $4 \%$ of cementations materials content to reduce the autogenously shrinkage.

11) The use of steel fibers contributes to mitigating the autogenously shrinkage by bridging effects inside the microstructure of UHPC and increases the compressive, tensile, and flexural strengths.

12) The use of basalt fibers contributes to mitigating the autogenously shrinkage significantly by bonding forces between the fibers and the matrix and increases the compressive strengths more than what steel fibers do, but tensile and flexural slightly increased.

\section{Abbreviations}

Cem: Cement

FA: Fly ash

$f^{\prime} c f:$ Cylinder's compressive strength of fibrous concrete

frf: Prism's modulus of rupture of fibrous concrete

fspf: Cylinder's splitting tensile strength of fibrous concrete

HRWRA: High range water reducing admixture

SF: Silica fume

UHPC: Ultra high performance concrete

UHSC: Ultra high strength concrete

Vf: Volume fraction of fibers

\section{Author contribution}

All authors contributed equally to this work.

\section{Funding}

This research received no specific grant from any funding agency in the public, commercial, or not-for-profit sectors.

\section{Data availability statement}

The data that support the findings of this study are available on request from the corresponding author.

\section{Conflicts of interest}

The authors declare that there is no conflict of interest. 


\section{References}

[1] F. de Larrard, T. Sedran, Optimization of ultra-high-performance concrete by the use of a packing model, Cem. Concr. Res., 24 (1994) 997-1009. https://doi.org/10.1016/0008-8846(94)90022-1

[2] E. Fehling, M. Schmidt, J. Walraven, T. Leutbecher, S. Frohlich, Ultra-high performance concrete, fundamentals, design, examples Beton Kalender, Wilhen Ernst and Sohn, Germany, (2014)188.

[3] ACI 239R. Ultra-high-performance concrete: An emerging technology report, American Concrete Institute, ACI 239, (2018).

[4] N. A. Azmee, N. Shafiq, Ultra-high performance concrete: From fundamental to applications, Case Stud. Constr. Mater., 9 (2018). https://doi.org/10.1016/j.cscm.2018.e00197

[5] R. Yu, P. Spiesz, H. J. H. Brouwers, Mix design and properties assessment of ultra-high performance fiber reinforced concrete (UHPFRC), Cem. Concr. Res., 56 (2014) 29-39. https://doi.org/10.1016/j.cemconres.2013.11.002

[6] F. De Larrard, t. Sedran, Mixture-proportioning of high-performance concrete, Cem. Concr. Res., 32 (2002) $1699-1704$. https://doi.org/10.1016/S0008-8846(02)00861-X

[7] S. A. A. M. Fennis, J. C. Walraven, J. A. Den Uijl, The use of particle packing models to design ecological concrete, Heron, 54 (2009)183-20.

[8] O. A. Abd, Mechanical properties of high strength concrete containing different cementations materials, Eng. Technol. J., 34 (2016) 96-110. http://dx.doi.org/10.30684/etj.34.1A.9

[9] A. Al-Ghaban, H. Jaber, and A. Shaher, Investigation of addition different fibers on the performance of cement mortar, Eng. Technol. J., 36 (2018) 957-965. http://dx.doi.org/ 10.30684/etj.36.9a.3

[10] M. Al-Ghaban and H. A. Jaber, A comparative investigation on mechanical properties of various fibers reinforced concrete, Eng. Technol. J., 37 (2019) 28-36. https://doi.org/10.30684/etj.37.1A.5

[11] J. Liu, C. Shi, Z. Wu, Hardening, microstructure, and shrinkage development of UHPC: A review, ACF. Journal., 5 (2019) 1-19. https://doi.org/10.18702/acf.2019.12.5.2.1

[12] P. Lura, O.M. Jensen, K. van Breugel, Autogenous shrinkage in high-performance cement paste: an evaluation of basic mechanisms, Cement Concr. Res., 33 (2003) 223-232. https://doi.org/10.1016/S0008-8846(02)00890-6

[13] A. Kamen, Time dependent behavior of ultra-high performance fiber reinforced concrete (UHPFRC), (2006) 1-8.

[14] L. Yang, C. Shi, and Z. Wu, Mitigation techniques for autogenously shrinkage of ultra-high-performance concrete - A review, Compos. Part. B. Eng., 178 (2019) 107456. https://doi.org/ 10.1016/j.compositesb.2019.107456

[15] T. Xie, C. Fang, M. S. Mohamad Ali, and P. Visintin, Characterizations of autogenously and drying shrinkage of ultrahigh performance concrete (UHPC): An experimental study, Cem. Concr. Compos., 91 (2018) 156-173. https://doi.org/ 10.1016/j.cemconcomp.2018.05.009

[16] S. Han, Y. Cui, H. Huang, M. An, Z. Yu, Effect of curing conditions on the shrinkage of ultra-high-performance fiberreinforced concrete, Adv. Civ. Eng., (2018). https://doi.org/10.1155/2018/5238278

[17] ASTM International, ASTM C 150/ C150M-15 Standard specification for Portland cement, ASTM. Int., (2015) 1-9. https://doi.org/ 10.1520/C0150

[18] ASTM International, ASTM C 1240-05Standard specification for silica fume used in cementations mixtures, ASTM. Int ., (2005) $1-7$.

[19] ASTM International, ASTM C 618-12aStandard specification for coal fly ash and raw or claimed natural pozzolan for use in concrete, AST. Mint., (2012)1-5.

[20] Arora, A. Almujaddidi, F. Kianmofrad, B. Mobasher, and N. Neithalath, Material design of economical ultra-high performance concrete (UHPC) and evaluation of their properties, Cem. Concr. Compos., 104 (2019) 103346. https://doi.org/ 10.1016/j.cemconcomp.2019.103346 